\title{
Sexually dimorphic extinction of a conditioned taste aversion in rats
}

\author{
KATHLEEN C. CHAMBERS \\ University of Washington, Seattle, Washington 98195 \\ and \\ CORD B. SENGSTAKE \\ Portland State University, Portland, Oregon 97207
}

\begin{abstract}
The existence of a sexual dimorphism in the extinction of conditioned taste aversions in both fluid-deprived and nondeprived rats was investigated. When nondeprived rats were poisoned with $\mathrm{LiCl}$ after consuming a sucrose solution, males extinguished the subsequent conditioned taste aversion more slowly than females. There was no difference in the rate of extinction of a $\mathrm{LiCl}$-induced conditioned taste aversion in fluid-deprived rats. Using marihuana extract distillate as the toxin, it was shown that the dimorphism found in the nondeprived rats is not a toxin-specific effect, and does not appear to be due to the males being made more ill. Possible explanations for the appearance of the dimorphism and its relation to the deprivational state of the organism are discussed.
\end{abstract}

There has been a great deal of interest in sexual dimorphisms in reproductive behavior of both human and infrahuman organisms for some time, while the interest in nonreproductive sexually dimorphic behaviors has been limited largely to studies using human subjects. Recently, however, this interest in sexual dimorphisms in nonreproductive behaviors in infrahuman subjects has increased, partly because of the application of the embryological model of sexual differentiation to such behaviors (Goy \& Goldfoot, 1973; Harris, 1964; Young, Goy, \& Phoenix, 1964). Another reason is the growing interest in the field of behavioral genetics; sex-linked behaviors present a relatively simple and therefore useful research model.

Previously, sexual dimorphisms have been reported in a few different types of avoidance behaviors. Beatty and Beatty (1970) and Levine and Broadhurst (1963) found that female rats performed better in the acquisition of a shock avoidance response. Hoshishima (1967) reported that female mice have a lower tolerance for a bitter taste. Finally, it has been shown that female humans report more food aversions than males (Byrne, Golightly,

This work was supported in part by National Science Foundation Grant GB-40314 to Robert C. Bolles and by United States Public Health Grant DA 00622 to Cord B. Sengstake. The authors wish to thank Robert C. Bolles and Stephen $C$. Woods for their helpful comments. A portion of this paper was presented at the 1973 Western Psychological Association meeting, Anaheim, California. Requests for reprints should be sent to Kathleen C. Chambers, Department of Psychology, Portland State University, P.O. Box 751, Portland, Oregon 97207.
\& Capaldi, 1963; Smith, Powell, \& Ross, 1955a, b; Wallen, 1943).

One might therefore expect to find sexual dimorphisms in conditioned taste aversions. However, investigators who have used both sexes when studying conditioned taste aversions have reported no sexual dimorphic behaviors in either acquisition (Nachman, 1970) or extinction (Green, 1969). In both of these studies, rats were under high fluid deprivation, and it has been shown that such rats show a more rapid extinction of the aversions than those under low fluid deprivation (Grote \& Brown, 1971). If extinction occurs very rapidly, any existing sexual dimorphism in the rate of extinction may be obscured.

\section{EXPERIMENT I}

\section{Method}

In order to minimize the rate of extinction of the conditioned taste aversion, and thereby increase the likelihood of finding a dimorphism, Experiment I was designed to examine conditioned taste aversions in female and male rats under ad lib food and water conditions.

Sixteen Sprague-Dawley-derived rats (75-90 days old) were randomly assigned to one of two drug conditions with four females and four males per condition. The rats had been housed in colony cages on ad lib food and water since weaning. About 3 weeks before the start of the experiment, they were moved to individual cages. Throughout their lives, they were kept on a 12-h light/dark cycle.

The experiment consisted of a preparatory period and an experımental period. During both of these periods, the animals were maintained on ad lib food and water, and they were weighed daily just prior to the end of the light portion of the light/dark cycle. The preparatory period lasted for 


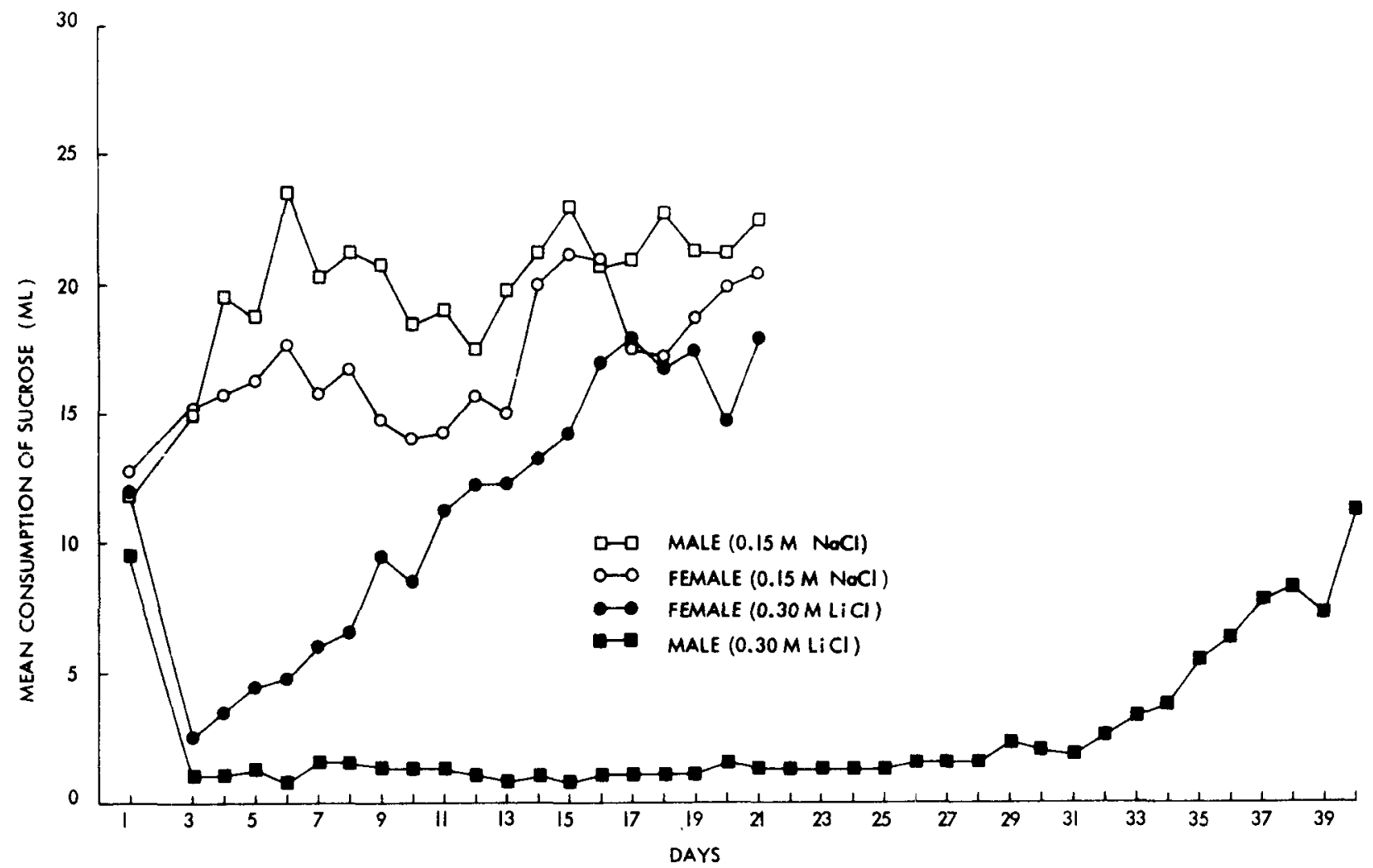

Figure 1. Mean consumption of sucrose for nondeprived females and males before (Day 1) and after (Days 3-40) injection of $\mathrm{NaCl}$ or $\mathbf{L i C l}$.

12 days. Durnng the first 6 days, the rats were only weighed. For the next 6 days, in addition to being weighed, therr water was replaced with fresh tap water at the beginning of the dark portion of the cycle. The experimental period of the experiment started immediately after the termination of the preparatory period. A $10 \%(\mathrm{w} / \mathrm{v})$ sucrose solution was mixed and stored under refrigeration $24 \mathrm{~h}$ before it was to be given to the rats. This solution was always given at the beginning of the dark phase of the light cycle. On Day 1 (acquisition) of the experimental period, the rats' water was replaced with the sucrose solution for $2 \mathrm{~h}$. At the end of the 2-h period, the amount of solution consumed was recorded for each rat. Immediately after access to the sucrose, half of the females and half of the males were injected (IP) with a $0.30 \mathrm{M} \mathrm{LiCl}$ solution in the quantity of $20 \mathrm{ml} / \mathrm{kg}$. The remainıng animals were injected (IP) with a normal salıne solution $(0.15 \mathrm{M} \mathrm{NaCl})$ in the same quantity. Following the injections, the anmals were returned to their cages, and the sucrose solution was replaced with fresh tap water. On Day 2, the rats' water was replaced with fresh tap water at the beginning of the dark phase of the light cycle. On Days 3-21 (extinction), the water of all rats was replaced with the sucrose solution. After $2 \mathrm{~h}$, the amount of sucrose solution was recorded and the sucrose was replaced with fresh tap water

\section{Results}

The consumption data from Days 1 and 3 of the experimental period were analyzed using a two-factor (Time by Drug) analysis of variance with repeated measures on time. Those animals injected with $\mathrm{NaCl}$ increased their consumption of sucrose from Day 1 10 Day 3, whereas those rats injected with $\mathrm{LiCl}$ decreased consumption, $F(1,12)=32.89, p<.01$. Thus, rats injected with $\mathrm{LiCl}$ acquired a conditioned taste aversion (see Figure 1).
The number of days each $\mathrm{LiCl}$ animal drank less than $50 \%$ of its Day 1 consumption was calculated. Females began to consume $50 \%$ of their Day 1 consumption sooner than the males, $t(6)=9.69$, $\mathrm{p}<.01$. Figure 1 shows that the $\mathrm{LiCl}$ females' mean consumption reached $50 \%$ of Day 1 by Day 7 and $100 \%$ of Day 1 by Day 12. The LiCl males, on the other hand, still showed a strong aversion by the end of Day 21. The extinction trials for this one group of animals were therefore continued, using exactly the same procedures as were used during Days 3-21, until all of the rats regained their Day 1 consumption levels. During this extension of the extinction trials, the $\mathrm{LiCl}$ males' mean consumption reached $50 \%$ of Day 1 on Day 35 and $100 \%$ on Day 40 .

\section{EXPERIMENT II}

The results of Experiment I indicate that there is a sexual dimorphism in the rate of extinction from conditioned taste aversions in nondeprived rats: males extinguish more slowly than females. Our finding differs from that of Green (1969), who reported no difference in extinction in deprived rats. The following experiment will attempt to replicate Green's finding.

\section{Method}

Thirty-two rats were randomly assigned to one of the two drug 
conditions with eight females and eight males per condition. More rats were used per condition in this experiment because of the insensitivity of the testing procedure with fluid-deprived animals. The conditions and procedures of the preparatory and the experimental periods were identical to those of Experiment I, except as noted.

On Day 6 of the preparatory period, water deprivation was initiated $3 \mathrm{~h}$ after the beginning of the dark phase of the light cycle. At the beginning of the dark portion of the cycle on Days 7.12 of the preparatory period, all rats were given access to fresh tap water for $3 \mathrm{~h}$. On Day 1 of the experimental period (acquisition), the animals were given access to the sucrose solution for $2 \mathrm{~h}$ and then injected with either $\mathrm{LiCl}$ or $\mathrm{NaCl}$. No additional water was given on Day 1. On Day 2, the rats were given access to fresh tap water for $3 \mathrm{~h}$. On Days 3-9 (extinction), the rats were first given access to the sucrose solution for $2 \mathrm{~h}$ and then access to fresh tap water for $1 \mathrm{~h}$.

\section{Results}

The amounts of the sucrose solution consumed on Day 1 were compared with the amounts consumed on Day 3 using a two-factor (Time by Drug) analysis of variance with repeated measures on time. Those rats injected with $\mathrm{NaCl}$ increased their consumption from Day 1 to Day 3, whereas the rats injected with $\mathrm{LiCl}$ decresed consumption, $\mathrm{F}(2,42)=$ $60.09, \mathrm{p}<.01$. Thus, the $\mathrm{LiCl}$ animals acquired a conditioned taste aversion (see Figure 2).

The number of days each $\mathrm{LiCl}$-injected rat drank less than $50 \%$ of Day 1 consumption was calculated. There was no difference in the amount of time required for females and males to begin to consume at least $50 \%$ of their Day 1 consumption, $\mathrm{t}(14)=$ 0.35 . Figure 2 shows that both female and male $\mathrm{LiCl}$ animals' mean consumption of the sucrose solution reached at least $50 \%$ of their Day 1 consumption by Day 4 and at least $100 \%$ by Day 5 .

\section{EXPERIMENT III}

Dragoin (1971) and Elkins (1973) have found that rats given high dosage levels of a drug take longer to extinguish a conditioned taste aversion than those given low dosage levels. It is possible that the nondeprived males in Experiment I took longer to extinguish than the females because the males were made more ill. This explanation would be made much less plausible, however, if females, given a higher dosage level (in terms of $\mathrm{mg} / \mathrm{kg}$ ) than males, still showed a more rapid extinction. Experiment III permits a comparison of the extinction in females and males given only half the dosage level. A marihuana extract, rather than $\mathrm{LiCl}$, is used as the toxin (Elsmore \& Fletcher, 1972) in order to show also that the sexually dimorphic behavior observed in Experiment $I$ is not a toxin-specific effect.

\section{Method}

Thirty-six rats were randomly assigned to one of three dosage levels with six females and six males per level. The conditions

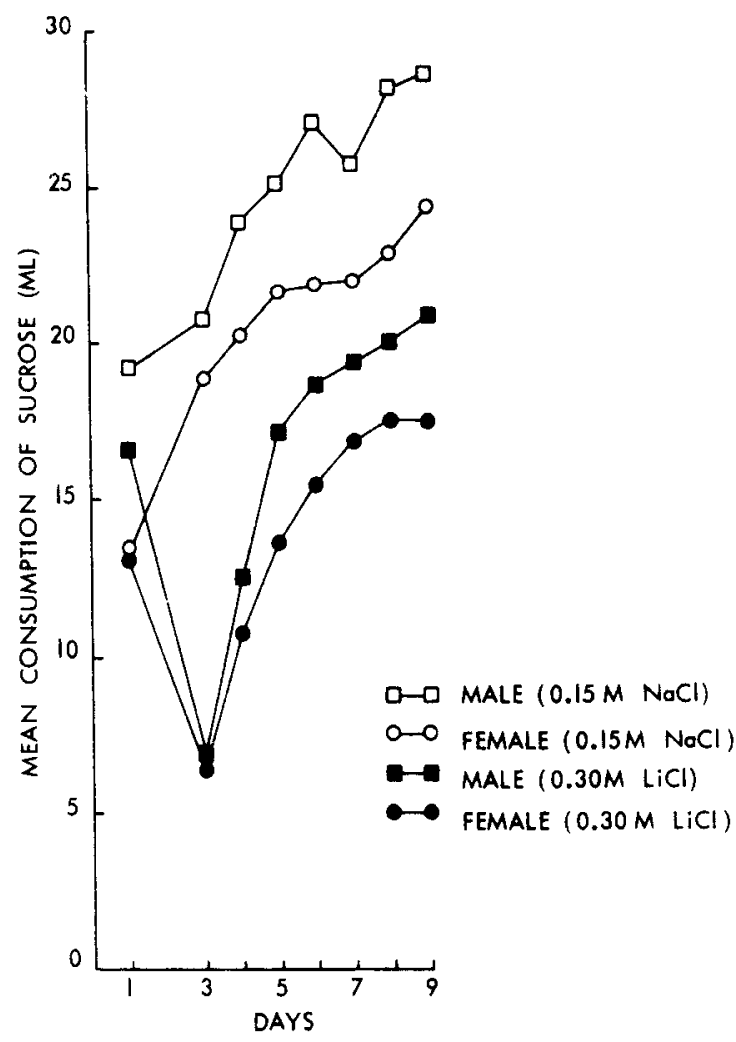

Figure 2. Mean consumption of sucrose for fluid-deprived females and males before (Day 1) and after (Days 3-9) injection of $\mathrm{NaCl}$ or $\mathrm{LiCl}$.

and procedures of the preparatory and the experimental periods were identical to those of Experiment $I$, except as noted. The toxin used as marihuana extract distillate (MED ${ }^{1}$ ) in a carrier solution consisting of $0.9 \% \mathrm{NaCl}(\mathrm{w} / \mathrm{v})$ and $4 \%$ tween-80 (polyoxyethylene sorbital mono-oleate) $(\mathrm{v} / \mathrm{v})$ in distilled water. The dosage levels of the MED, specified in terms of the amount of delta-9-tetrahydrocannabinol (THC), were 0.0 (the carrier solution), 4.0 , and $8.0 \mathrm{mg} / \mathrm{kg}$. The injections were made in the amount of $1 \mathrm{ml} / \mathrm{kg}$ regardless of the dosage level. The experimental period was termınated after Day 14.

\section{Results}

The amounts of sucrose solution consumed on Day 1 of the experimental period was compared with those consumed on Day 3 using a two-factor (Time by Dose) analysis of variance with repeated measures on time. Most rats injected with $0.0 \mathrm{mg} / \mathrm{kg}$ increased their consumption of sucrose during this period, whereas all rats injected with 4.0 or $8.0 \mathrm{mg} / \mathrm{kg}$ decreased consumption, $\mathrm{F}(2,30)=34.08$, $p<.01$. Thus, the effects of the MED led to the formation of a conditioned taste aversion. (See Figure 3.)

The number of days each MED-injected rat drank less than $50 \%$ of its Day 1 consumption was calculated. All animals still showing an aversion on Day 14 were assigned a score of 15 days. The data were analyzed using a two-factor (Sex by Dose) analysis of variance. Both groups of MED-injected females reached $50 \%$ of their Day 1 consumption 


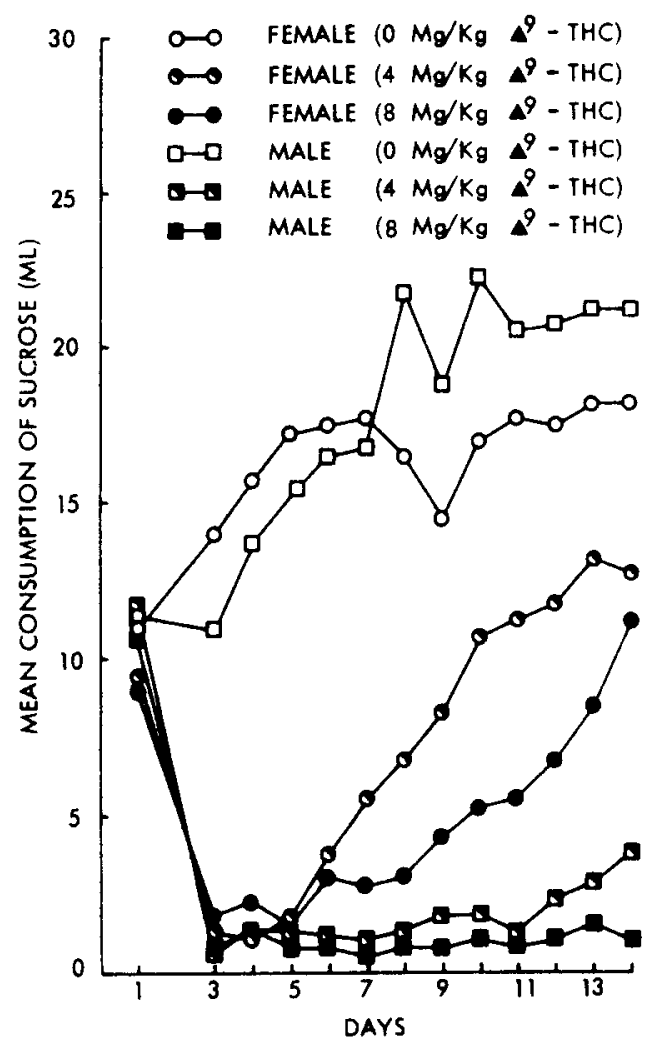

Figure 3. Mean consumption of sucrose for nondeprived females and males before (Day 1) and after (Days 3-14) injection of the carrier solution or MED.

sooner than did either of the groups of males, $F(1,20)=19.78 . \mathrm{p}<.01$. Figure 3 shows that the mean consumption by females given $4.0 \mathrm{mg} / \mathrm{kg}$ delta-9-THC reached $50 \%$ of Day 1 by Day 7 and $100 \%$ by Day 10 and the mean consumption by females given $8.0 \mathrm{mg} / \mathrm{kg}$ reached $50 \%$ by Day 9 and $100 \%$ by Day 14. Most of the males were still showing the aversion at the end of the experimental period. Of special interest is that the females receiving $8 \mathrm{mg} / \mathrm{kg}$ extinguished more rapidly than did the males receiving only $4 \mathrm{mg} / \mathrm{kg}, \mathrm{t}(10)=$ $2.58, \mathrm{p}<.05$.

\section{DISCUSSION}

When rats are tested under ad lib water conditions, males extinguish a conditioned taste aversion more slowly than do females. This sex difference does not seem to be a toxin-specific effect, since males take longer than females whether the toxin is $\mathrm{LiCl}$ or MED. It also seems unlikely that this dimorphism is due to the males' being made more ill, since the females receiving $8 \mathrm{mg} / \mathrm{kg}$ MED recovered from the aversion sooner than did males receiving $4 \mathrm{mg} / \mathrm{kg}$. It should also be noted that females, in a number of different behavioral tasks, have consistently been shown to be more affected by marihuana than males (Carlmi \& Masur, 1969; Cohn, Barrat, \& Pirch, 1972).

A number of investigators have found that female rats have a greater preference for sweet solutions (in a 24-h test) than males (Valenstein, Cox, \& Kakolewski, 1967; Valenstein, Kakolewski, \& Cox, 1967; Wade \& Zucker, 1969). It is possible that the faster extinction of the females in Experiments I and III reflects this greater preference for the sugar water. However, if the amount consumed can be used as a measure of preference, the data from the control females and males in Experiments I and III indicate no sex difference in the preference for sucrose. In addition, Chambers and Thrower (Note 1) have found that when both nondeprived and fluid-deprived rats are given a choice between water and sucrose for $2 \mathrm{~h}$, both fermales and males show a total, i.e., $100 \%$, preference for sucrose. This leads us to believe, at least for a 2-h test, that there is no sex difference in the preference for a $10 \%$ sucrose solution as measured by either amount or percent consumed. A further argument against explaining the more rapid extinction by the females as due to their greater preference for sweet tastes stemis from the findings by several investigators that conditioned taste aversions are stronger for a preferred flavor than for a nonpreferred flavor (Green \& Churchill, 1970; Wittlin \& Brookshire, 1968). If females do have a greater preference for the sucrose solution, then these findings would suggest that the females, and not the males, should have taken longer to extinguish.

Although there was a clear sex difference in the rate of extinction of the nondeprived rats, the deprived rats in Experiment II failed to show even a suggestion of a sex difference. This supports our view that the failure to detect a sex difference in other experiments may have been due to the very rapid extinction of avoidance in all of the animals. Most of the rats in Experiment II regained their Day 1 consumption levels within two or three extinction trials. Thus, it may be that a sex difference existing in these deprived animals was obscured by this rapid extinction. It is also possible, of course, that there is no sex difference in deprived rats. This possibility, if true, would suggest that the sexually dimorphic behavior described in this paper is dependent upon the deprivational state of the organism.

\section{REFERENCE NOTES}

1. Chambers, K. C. \& Thrower. J. H. Ettects of deprivation state on extinction of conditioned taste aversions in female and male rats. Unpublished manuscript. 1975, Available from Department of Psychology. Portland State University, Portland. Oregon 97207). 


\section{REFERENCES}

BeAtтy, W. W., \& Beatty, P. A. Hormonal determinants of sex differences in avoidance behavior and reactivity to electric shock in the rat. Journal of Comparative and Physiological Psychology, 1970, 73, 446-455.

Byrne, D., Golightly, C., \& Capaldi, E. J. Construction and validation of the food attitude scale. Journal of Consulting Psychology, 1963, 27, 215-222.

Carlini, E. A., \& Masur, J. Development of aggressive behavior in rats by chronic administration of Cannabis sativa (marihuana). Life Sciences, 1969, 8, 607-620.

Cohn, R. A., Barratt, E., \& Pirch, J. H. Differences in behavioral responses of male and female rats to marijuana. Proceedings of the Society for Experimental Biology and Medicine, 1972, 140, 1136-1139.

Dragoliv, W. B. Corditioning and extinction of taste aversions with variatrons in intensity of the CS and UCS in two strains of rats. Psychonomic Science, 1971,22, 303-304.

Elkins. R. L. Individual differences in bait shyness: Effects of drug dose and measurement technique. The Psychological Record, 1973, 23, 349-358.

Elsmore, T. F., \& Fietcher, G. V. $\Delta^{9}$-Tetrahydrocannabinol: Aversion effects in rat at high-doses. Sclence, 1972, 175, $911-912$.

Goy, R. W., \& Goldfoot, D. A. Hormonal influences on sexually dımorphic behavior. In R. O. Greep (Ed.), Handbook of physiology (Section 7, Vol. 2, Part 1). Washington D.C: American Physiological Society, 1973.

GREEN, K. F. Aversions to grape juice induced by apomorphine. Psychonomic Sclence, 1969, 17, 168-169.

Green, K. F., \& Churchill, P. A. An effect of flavors on strength of conditioned aversions. Psychonomic Science, 1970. 21, 19-20.

GRote, F, W., JR., \& Brown, R. T. Conditioned taste aversions: Two-stimulus tests are more sensitive than one-stimulus tests. Behavioral Research Methods \& Instrumentation, 1971, 3, 311-312.

HaRris, G. W. Sex hormones, brain development and brain function. Endocrinology, 1964, 75, 627-648.

Hoshishima, K. Endocrines and taste. In M. R. Kare \& $O$. Maller (Eds.). The chemical senses and nutrition. Baltimore: John Hopkins Press, 1967.
Levine. S., \& Broadhurst, P. L. Genetic and ontogenetic determinants of adult behavior in the rat. Joumal of Comparative and Physiological Psychology, 1963, 56, 423-428.

NACHMAN, M. Learned taste and temperature aversions due to lithium chloride sickness after temporal delays. Journal of Comparative and Physiological Psychology, 1970, 73, 22-30.

Smith, W., Powell, E. K., \& Ross, S. Manifest anxiety and food aversions. Journal of Abnormal and Social Psychology, 1955, 50, 101-104. (a)

Smith, W. L., Powell, E. K., \& Ross, S. Food aversions: Some additional personality correlates. Journal of Consulting Psychology, 1955, 19, 145-149. (b)

Valenstein, E. S., Cox, V. C., \& Kakolewski, J. W. Further studies of sex differences in taste preferences with sweet solutions. Psychological Reports, 1967, 20, 1231 1234.

Valenstein, E. S., Kakolewski, J. W.. \& Cox, V. C. Sex differences in taste preference for giucose and saccharin solutions. Science, 1967, 156, 942-943.

WADE, G. N., \& ZuCKER, I. Hormonal and developmental influences on rat saccharin preferences. Journal of Comparative \& Physiological Psychology, 1969, 69, 291-300.

W Allen, R. Sex differences in food aversions. Journal of A pplied Psychology, 1943, 27, 288-298.

Wittlin, W. A., \& Brookshire, K. B. Apomorphine-induced conditioned aversions to a novel food. Psychonomic Science, $1968,12,217-218$.

Young. W. C., Goy. R. C., \& Phoenix, C. H. Hormones and sexual behavior. Science, 1964, 143, 212-218.

\section{NOTE}

1. The MED was supplied by the Center for Studies of Narcotic and Drug Abuse. United States Public Health Service, Rockville, Maryland 20852.

(Received for publication June 13, 1975; accepted November 5,1975 .) 